\title{
Structural analysis of deep soil loosening machine MAS-65
}

\author{
Mihai Gabriel Matache ${ }^{1 *}$, Remus Marius Oprescu ${ }^{1}$, Dragos Nicolae Dumitru ${ }^{1}$ and Gabriel \\ Valentin Gheorghe ${ }^{2}$, Dan Cujbescu ${ }^{1}$, Cătălin Persu ${ }^{1}$ \\ ${ }^{1}$ INMA Bucharest, Testing Department, 013813 Bucharest, Romania \\ ${ }^{2}$ INMA Bucharest, Soil Laboratory, 013813 Bucharest, Romania
}

\begin{abstract}
Deep soil loosening machine MAS 65 is destined to work soil at depths exceeding $45 \mathrm{~cm}$, thus the machine's frame is subjected to loads which could affect its structural integrity. Within this paper a static structural analysis was performed on the machine's 3D model using finite element method and strain and stress distribution maps were created. Using the Von Mises stress map there were identified several critical points which could fail during normal exploitation conditions and which should be monitored by strain gages during field tests in order to prevent structural failure.
\end{abstract}

\section{Introduction}

Agricultural machinery are self-propelled working machines or driven from alternative power sources, designed for performing a series of works within agricultural processes, according to agricultural-biological and technical-economical requirements imposed.

Generally, conception of an agricultural machine starts from its physical operations which have to be executed during operation. Conception could be new, innovative which takes into consideration the state of the art of the working technologies (e.g. technologies for realization of no tillage soil works [1]), but also could be one inspired after a similar operation performed by an existent machine that we want to improve its performances [2]. The resistance structure, frame or chassis, is designed and dimensioned according to a strength reserve which assures the good development of the activity, choosing for it an adequate material [3] (so to be able to withstand maximum strain which does not affect the work quality and maximum loads in the structure which cannot cause damage). This primary structure is subjected to a first process of structural analysis for an improved or even optimal design $[4,5,6]$. This structural analysis process includes the following stages: structural modelling, static analysis, frequency analysis, dynamic simulation, fatigue analysis. After all, or some of these stages the final theoretical dimensioning of the structure could be finalized.

Because of the different loads frequency and amplitude characteristics and their number of cycles sustained by the mechanical resistance structure of agricultural machinery, these

\footnotetext{
* Corresponding author: gabimatache@yahoo.com
} 
could fail functionally or structurally. There are numerous examples in current practice which confirm the apparition possibility of this phenomenon. It is a known fact that the failing process of diverse structures, manufactured with diverse materials, is very complex and that there are fundamental differences between failing due to static loads and failing because dynamic loads. Thus, there were elaborated principles, methods of experimental research and calculus specific to both types of solicitations.

Failing or breaking because static solicitations is produced on a structure when it reaches the yield tension of a material or it is exceeded the limit breaking tension of the respective material.

Failing or breaking because dynamic solicitations is produced in function of the shock solicitation when it's reached the yield point of a material or it's exceeded the limit breaking tension of the respective material or by material fatigue phenomenon. Also, of great importance are the material binding procedures (with screws and nuts, with rivets or through welding) [7].

Structures fail when under-dimensioned, if there are exceeded the specified loading characteristics in their user manual or if they were designed to fail as a precautious measure. In the design stage is very important to dimension the structure for operating in complete elasticity conditions.

\section{Material and method}

\subsection{Structural model of MAS-65 deep soil loosening machine}

Structural model of MAS-65 deep soil loosening machine was constructed in view of preliminary identification of critical points within its resistance frame. The model was developed using finite three-dimensional elements. The software used for modelling was SolidWorks [8], starting from the already developed experimental model of the machine. Thus, have been identified the principal components of the resistance frame: central beam, longerons, three-point linkage system to the tractor, support of the working body and the working body. Also, were identified the metallic profiles from which the experimental model was constructed through welding and we measured their dimensions, allowing to develop the structural model presented in figure2.

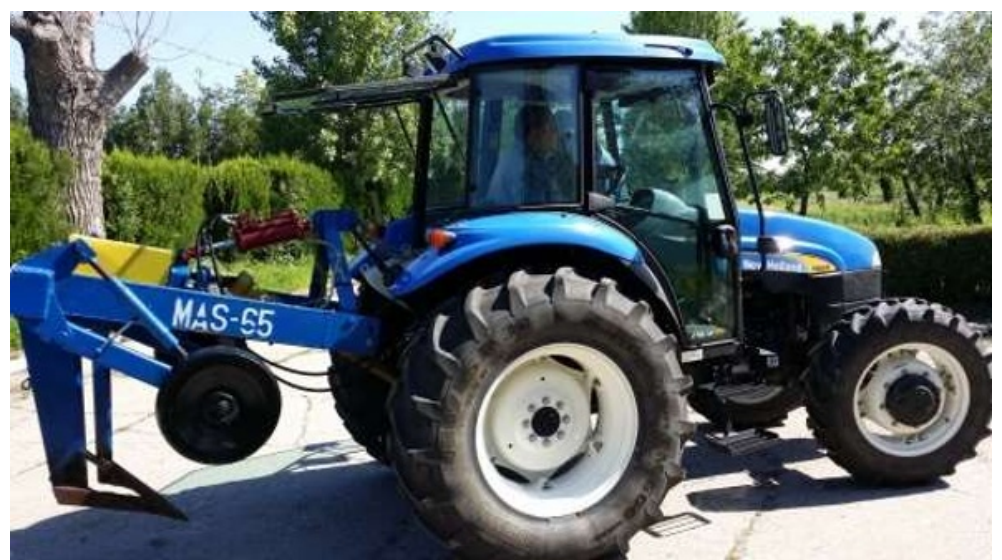

Fig. 1 MAS-65 experimental model in aggregate with New Holland TD80 tractor 


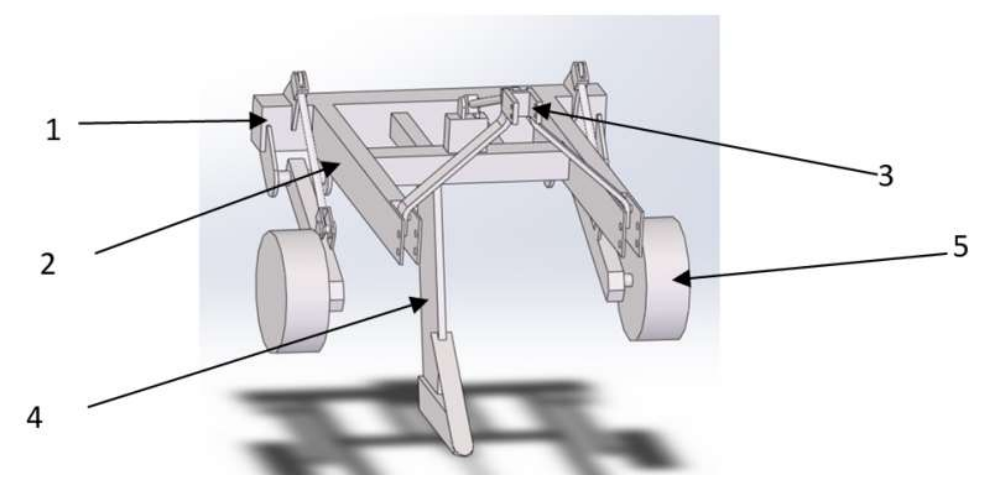

Fig. 2 Structural model of MAS-65 deep soil loosening machine: geometry and component elements ( 1 - central beam, 2 - longerons, 3 - three-point linkage system, 4 - working body organ support and working body, 5 - wheels for establishing working depths).

The material from which was constructed the experimental model chosen also for the structural model was carbon steel [9], with the following characteristics:

- yield strength $\sigma_{\mathrm{c}}=2.20594 \cdot 10^{8} \mathrm{~N} / \mathrm{m}^{2}$;

- ultimate tensile strength $\sigma_{\mathrm{r}}=3.99826 \cdot 10^{8} \mathrm{~N} / \mathrm{m}^{2}$;

- Young modulus $\mathrm{E}=2.1 \cdot 10^{11} \mathrm{~N} / \mathrm{m}^{2}$;

- Poisson coefficient $v=0.28$;

- material density $\rho=7800 \mathrm{~kg} / \mathrm{m}^{3}$;

- transversal elasticity modulus $\mathrm{G}=7.9 \cdot 10^{10} \mathrm{~N} / \mathrm{m}^{2}$

\subsection{Study properties in static regime}

We performed a structural analysis in static regime, using the solid type discretization. The discretized structure had a total number of 113081 nodes, with 59248 standard elements. Elements dimension was $54.5167 \mathrm{~mm}$ with a tolerance of $2.72584 \mathrm{~mm}$. Finite elements analysis was performed in Solidworks. In figure 3 is presented the discretized structure:

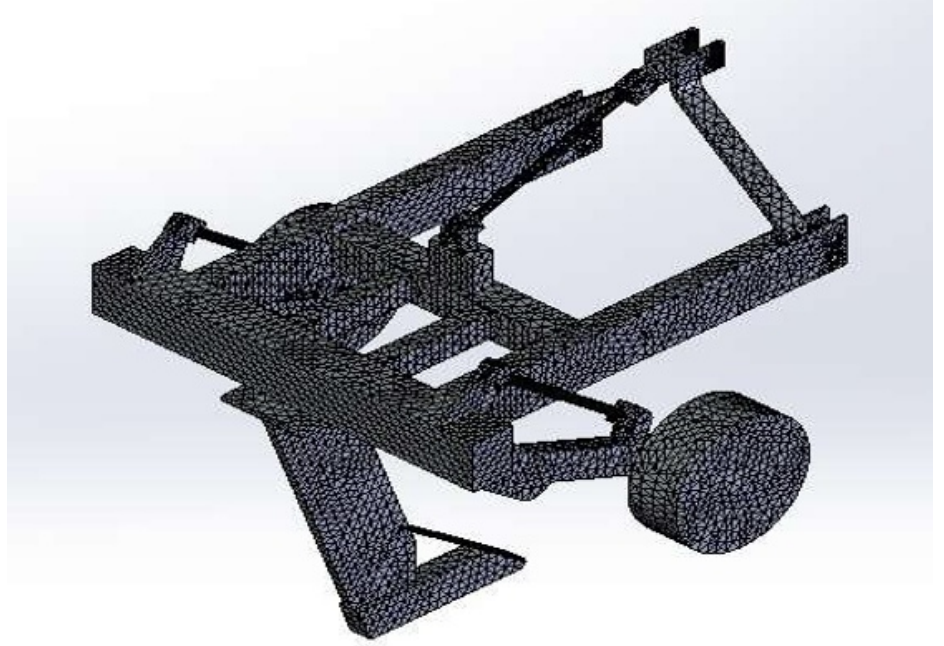

Fig. 3 Discretization of the MAS-65 structural model 
Loads and boundary conditions: the three fixtures in which were cancelled all the three translations (on orthogonal axes $\mathrm{Ox}$, Oy și $\mathrm{Oz}$ ) are corresponding to the three-point coupling system to the tractor existent on the physical model and were applied according to the following figure:

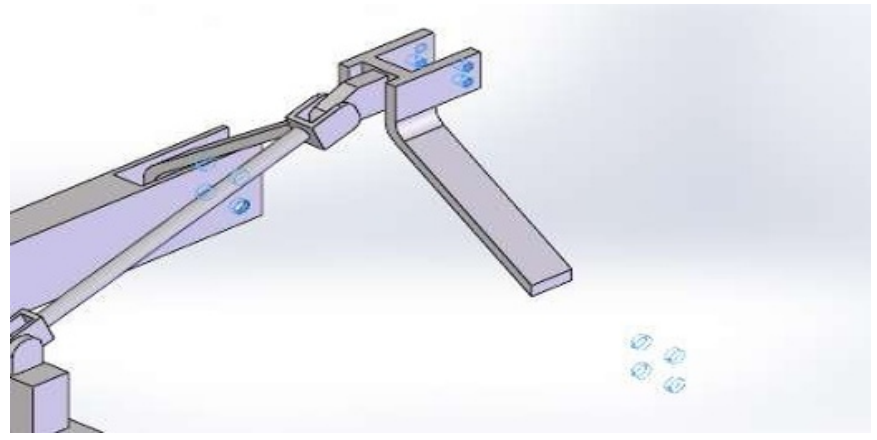

Fig. 4 Fixtures of MAS-65 structural model

The loading forces were applied on the working body, which consisted of 2 subassemblies (figure 5), on longitudinal direction in the plain corresponding with the forward movement of the machine. For the loading force on the working body chisel was selected a value of $9126 \mathrm{~N}$ while for the loading force on the edge of the working body was selected a value of de $4447 \mathrm{~N}$, after some estimation calculus according to [10]. Thus, the total reaction force in the fixture points achieved the value of $13573 \mathrm{~N}$.

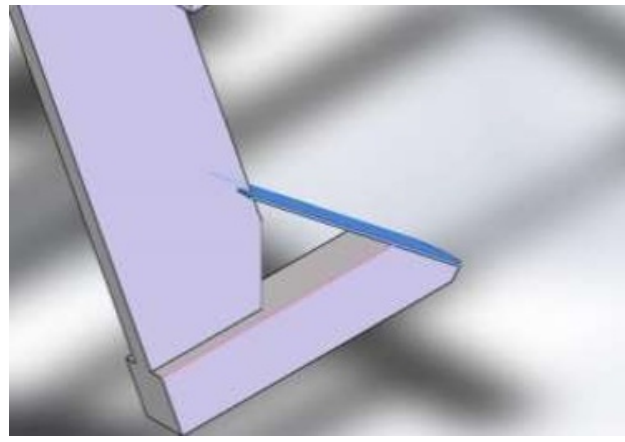

a)

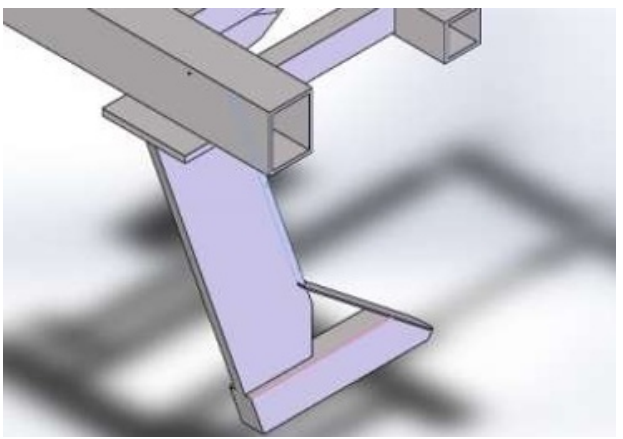

b)

Fig. 5 Loading forces on the working body: a) chisel of the working body; b) edge of the working body

\section{Results of the resistance study in static regime}

The minimum and maximum equivalent tensions (Von Mises) in the structural model were determined subsequent to the static analysis according to the fixtures and loads anteriorly presented. The maximum value of the equivalent tension was of $1.77389 \mathrm{e}+08 \mathrm{~N} / \mathrm{m}^{2}$ and was located in the central beam at the junction point with the working body organ, node 22155. The minimum value recorded was of $9793.72 \mathrm{~N} / \mathrm{m}^{2}$ and was located in node 40892 of discretized structure. 


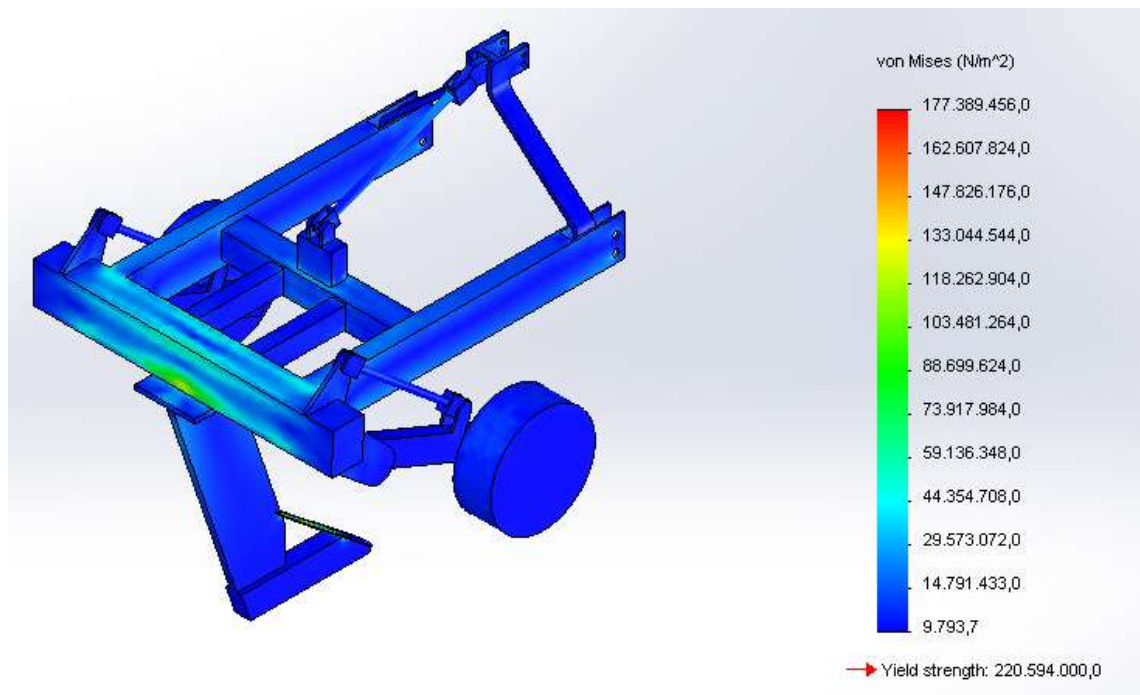

Fig. 6 Equivalent Von Misses tension map for MAS-65 structural model.

In figure 7 is graphically displayed the distribution of relative displacement values URES resulted in the structural model. Representation was realized on the deformed body of the structure. It could be observed the maximum values were located in the working body extremum, and the minimal ones in the fixture points to the tractor. The maximum value of the relative displacement resultant was of $5.79 \mathrm{~mm}$, located in node 21748 of the discretized structure.

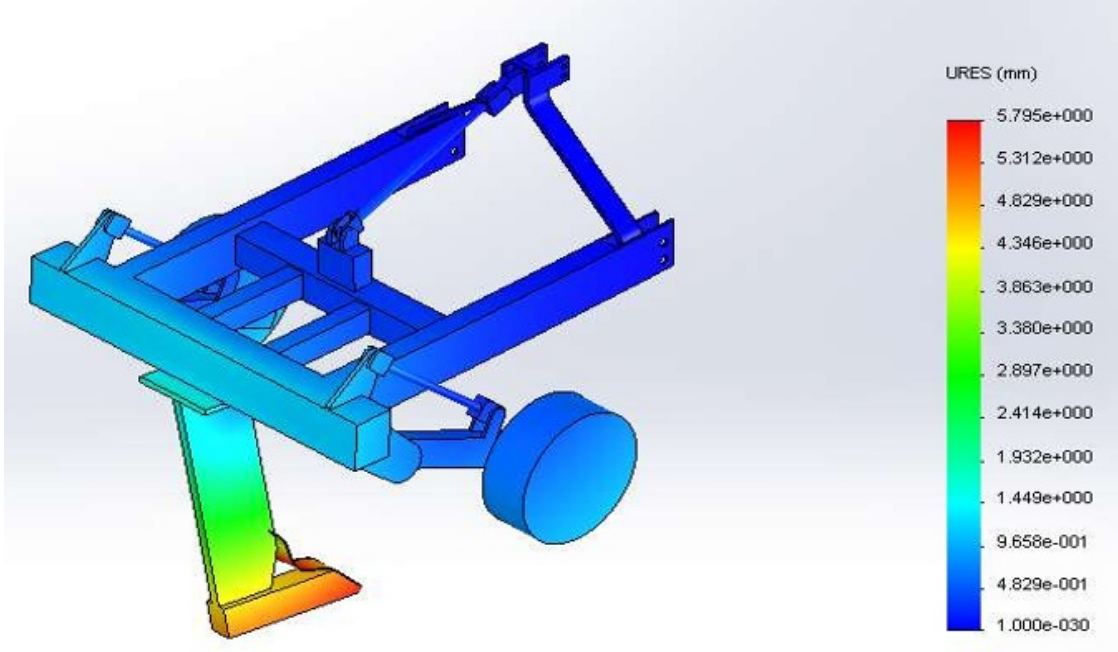

Fig. 7 Relative displacements map for MAS-65 structural model.

In the following figure is presented the map of equivalent strain ESTRN resulted after the static study. A minimum value of $5.65876 \mathrm{e}-008 \mathrm{~m} / \mathrm{m}$ was recorded in element 37669 and a maximum value of $0.000444062 \mathrm{~m} / \mathrm{m}$ in element 35453 . 

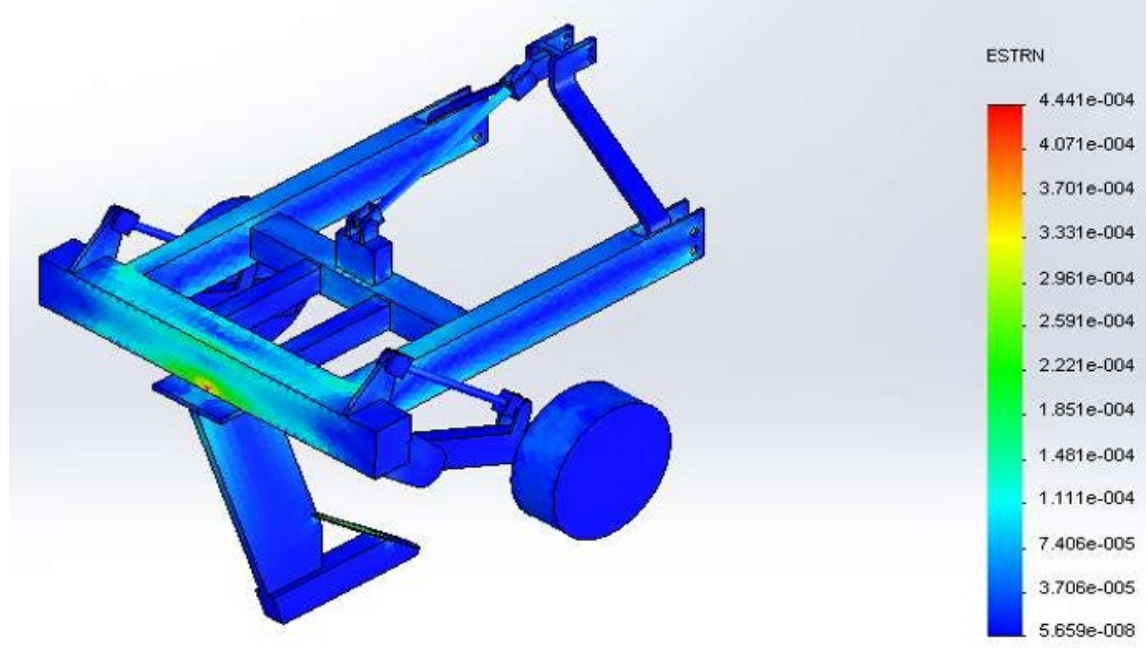

Fig. 8 Specific equivalent strain map for MAS-65 structural model $(\mathrm{m} / \mathrm{m})$.

After analysing the obtained results there were identified 14 critical points which could be subjected to critical failure in real exploitation conditions, for which the equivalent Von Misses tension was maximum. In figure 9 and 10 there are presented the 14 points located on the MAS- 65 structure. The points were named $\mathrm{M}_{\mathrm{i}}$, with $\mathrm{i}=1 \div 14$, the dimensions being given in millimetres. These points could be monitored using strain gages in real working conditions, using data acquisition.

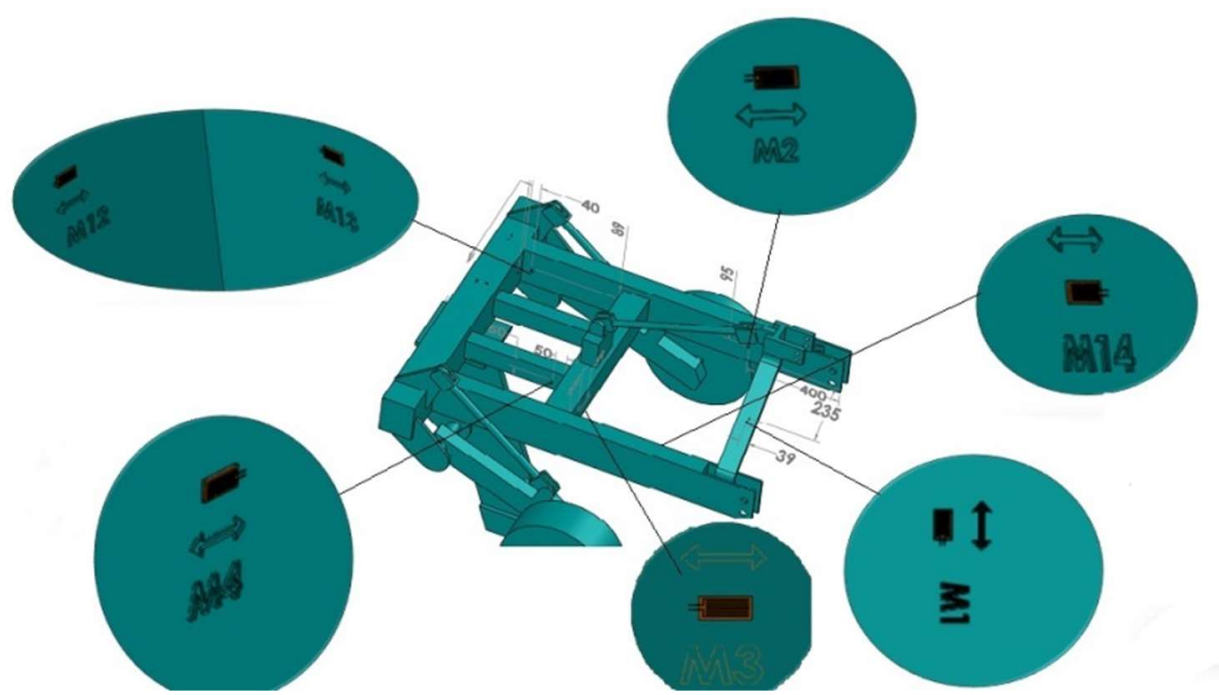

Fig. 9 Strain gage measuring points (M1, M2, M3, M4, M12, M13, M14). 


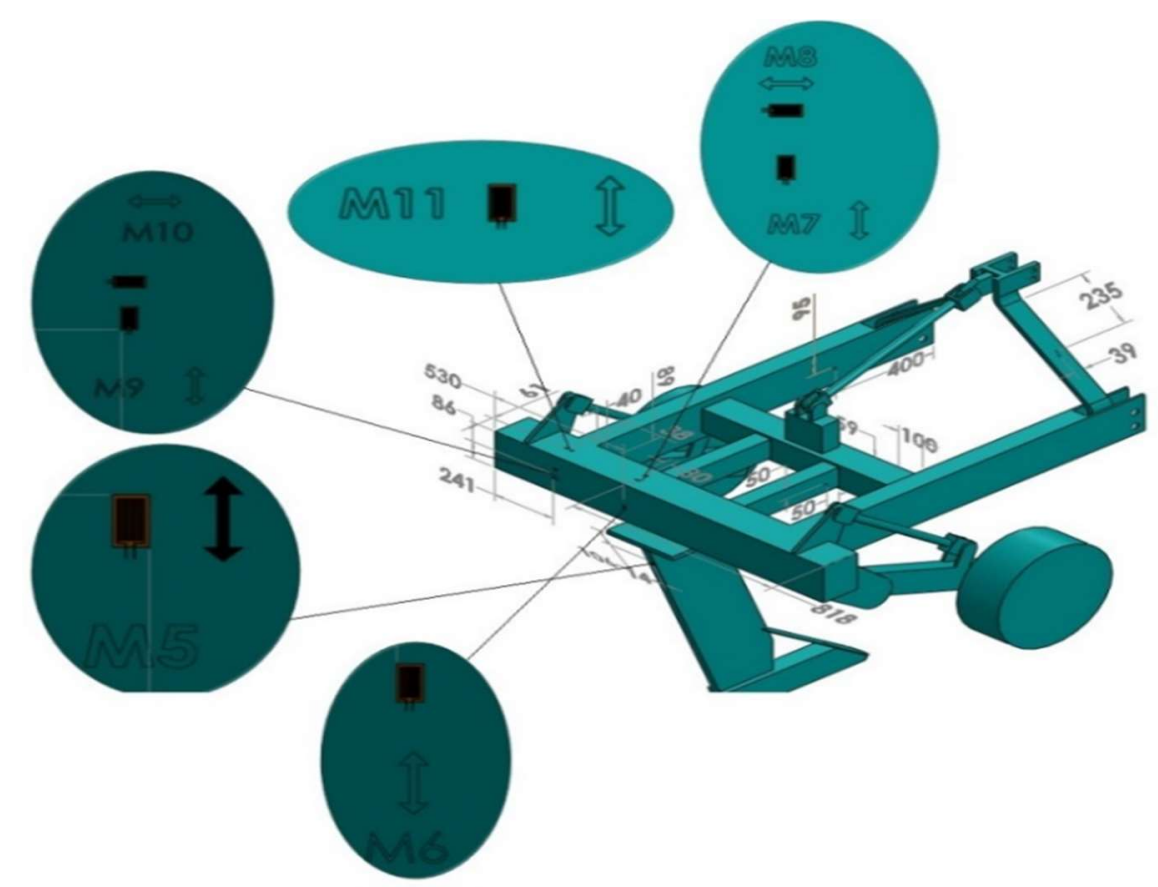

Fig. 10 Strain gage measuring points (M5, M6, M7, M8, M9, M10, M11).

In the following table there are presented the values obtained for the strain on axes Ox, Oy and $\mathrm{Oz}$ for the 14 critical points identified after finite element analysis of the structural model of MAS-65 deep soil loosening machine in static regime. There are presented all the three reference directions because for strain measuring could be used unidimensional strain gages or rosettes strain gage applied in the identified points. There were reported the values corelated with the direction of the strain gages so that to make possible their experimental value comparison after experiments will be performed.

Table1. Values of strain determined after FEM simulation

\begin{tabular}{|c|c|c|c|}
\hline $\begin{array}{c}\text { Critical point } \\
\text { identification }\end{array}$ & Ox strain- $\boldsymbol{\varepsilon}_{\mathbf{x}}(\boldsymbol{\mu m} / \mathbf{m})$ & Oy strain $-\mathbf{\varepsilon}_{\mathbf{y}}(\boldsymbol{\mu m} / \mathbf{m})$ & Oz strain $-\boldsymbol{\varepsilon}_{\mathbf{z}}(\boldsymbol{\mu m} / \mathbf{m})$ \\
\hline M1 & 64.35 & 147.31 & 45.3 \\
\hline M2 & - & - & -99.34 \\
\hline M3 & -98.99 & - & - \\
\hline M4 & - & -271.14 & -47.35 \\
\hline M5 & - & -28.64 & - \\
\hline M6 & - & - & - \\
\hline M7 & - & - & - \\
\hline M8 & 97.81 & 19.22 & - \\
\hline M9 & - & - & - \\
\hline M10 & 36.33 & - & - \\
\hline M11 & -345.25 & - & -39.24 \\
\hline M12 & 44.73 & - & -135.63 \\
\hline M13 & - & - & \\
\hline M14 & - & & \\
\hline
\end{tabular}




\section{Conclusions}

After the performed analysis there were identified critical areas of the resistance structure of the MAS-65 deep soil loosening machine. It was observed that the beam from the back of the equipment, which linked the two longerons of the resistance frame and on which was mounted the working body support, it was the most solicitated. Also, the chisel of the working body is heavily stressed in exploitation conditions.

After finite element analysis performed on the structural model of the equipment there were identified 14 critical points which could be chosen for applying of strain gages in view of future experimental analysis. Also, based on such recorded signals the finite analysis model could be validated.

\section{Acknowledgement}

This work was supported by a grant of the Romanian Research and Innovation Ministry, through Programme 1 - Development of the national research-development system, subprogramme 1.2 - Institutional performance - Projects for financing excellence in RDI, contract no. 16PFE.

\section{References}

1. I.D. Vlăduț, S. Şt. Biriş, et al. - State of the art regarding conservative tillage technologies, Annals of the University of Craiova - Agriculture, Montanology, Cadastre, Vol. 44, (2014)

2. L. Vlăduţoiu, V. Vlăduț, I. Voiculescu, et al. - The increase of active bodies of agricultural machines in work by hardening, Proceedings of the 43 International Symposium on Agricultural Engineering "Actual Tasks on Agricultural Engineering", pp $153 \div 164$, (2015)

3. K. Martensen - Progress în typical materials for agricultural machinery, Maschinenfabrik Bernard Krone, Spelle, Germany, http://www.clubofbologna.org/ew/documents/Martensen-paper.pdf.

4. R. Sfî̀ru, V. Vlădut, P. Cârdei, R. Ciupercă , M. Matache, V. Stefan, N. Ungureanu, Technical aspects regarding axles calculation of road transport means, Lambert Academic Publishing, (2014)

5. V. Vlăduţ, S. Şt. Biriş, et al. - The verification of stress by FEM analysis/mechanical testing of a traction bar, Proceedings of the 43 International Symposium on Agricultural Engineering "Actual Tasks on Agricultural Engineering", pp $141 \div 152$, , (2015)

6. E. Voicu, I. Cojocaru, G. Ciurel, S. Popescu - Experimental researches regarding the dynamic and energetic optimisation of the fodder trailed harvester CTF in aggregate with U-650 tractor, pp 73-79, INMATEH, Vol. 20, No. 2, (2007)

7. C. Th. Ploscariu- phd thesis: Researches and contributions regarding utilization and heat treatment of low alloy steels used for welded structures of Romanian helicopters, (2010)

8. SolidWorks Software Documentation.

9. C. Dumitrescu - Treaty of science and material engineering, Vol. 1, 2, 3, (2007)

10. V. Scripnic, P. Babiciu - Agricultural machinery, (1979) 